\title{
Effects of Electron Beam Irradiation on Impact Value of Borosilicate Glass
}

\author{
Keisuke Iwata* and Yoshitake Nishi \\ Department of Science and Technology, Doctoral Graduate School of Science and Engineering, \\ Tokai University, Hiratsuka 1259-1292, Japan
}

The effects of homogeneous irradiation of electron-beam (EB) with low voltage on the Charpy impact value $\left(a_{\mathrm{uc}}\right)$ of borosilicate glass were studied. When it performed in short bursts to maintain a low temperature, EB irradiation at a dosage from 0.04 to $0.22 \mathrm{MGy}$ increased the $a_{\mathrm{uc}}$ value and enhanced its reproducibly. Based on the electron spin resonance (ESR) spectra, EB-irradiation formed apparent dangling bonds constructed with sodium atoms with high density of outer-shell electrons and terminated oxygen atoms of silica network in the borosilicate glass. When the intermolecular repulsive force generated the partial relaxation against residual and deformed strain, as well as expansion in front of crack tips near the sodium atoms, the initial $a_{\mathrm{uc}}$ enhancement of the borosilicate glass by the irradiation can be explained. Furthermore, the strong resistance to radiation damage of borosilicate glass was qualitatively confirmed. Although the large start point of irradiation dose to decrease the $a_{\mathrm{s}}$ value was $0.08 \mathrm{MGy}$ for silica glass, it was $0.22 \mathrm{MGy}$ for borosilicate glass. Consequently, the boron addition enhanced the resistivity to irradiation damage. [doi:10.2320/matertrans.MAW200914]

(Received April 27, 2009; Accepted November 2, 2009; Published December 25, 2009)

Keywords: electron beam, impact value, borosilicate, glass, dangling bond

\section{Introduction}

Borosilicate glass can be used as thin glass of large-area liquid-crystal displays of televisions, ${ }^{1)}$ as well as an electronic insulator. However, the low fracture toughness of the glass has been a serious problem, when it is used to manufacture broad thin glassy sheets. ${ }^{2}$ ) Thus, strengthening transparent thin sheet glass is an important technique in manufacturing large-area liquid-crystal displays. ${ }^{1)}$

The brittle fracture, which is the result of nucleation and propagation of cracks, ${ }^{3-5)}$ is observed in steels, which is constructed with bcc iron and carbide, by deformation of both low temperature and high strain rate. Since it is very difficult to eliminate the crack origins, strengthening is often inhibited by crack propagation. ${ }^{6,7)}$ General strengthening has been performed by fiber reinforcement ${ }^{6)}$ and transformationinduced toughness. ${ }^{7)}$ Furthermore, it is useful to add residual compressive strain on the surface of the glass by physical and chemical reinforcement processes. ${ }^{8)}$ However, process conditions related to pressure, composition, temperature, time and dependent on the materials, must be selected in a complex manner.

On the other hand, the shot-peening is one useful tool to randomize the metallic glasses. ${ }^{9)}$ It enhances the saturated magnetization, ${ }^{10)}$ and also softens the glass, homogeneously. ${ }^{11)}$ However, it is difficult for shot-peening to randomize the ceramics without fracture.

To randomize the glassy network structure without fracture, irradiation by an electron beam (EB-irradiation), which has limited small mass, has been used as the ball of shot-peening. ${ }^{12,13)}$ Homogeneous EB-irradiation with lowvoltage generates dangling bonds ${ }^{12,13)}$ and then eliminates the crack, resulting in strengthening. ${ }^{12,13)}$ In addition, our research unit recently starts to report that the high stress resistance to crack origin nucleation as well as to crack propagation dominates the high fracture resistance of borosilicate glass. ${ }^{14)}$ However, the influence of EB-irradiation on the Charpy impact value $\left(a_{\mathrm{uc}}\right)$, one of indicator of practical

*Graduate Student, Tokai University fracture resistance, has not been reported for borosilicate glass. The $a_{\mathrm{uc}}$ value of a material is an important property in terms of practical applications. As a basic research, effects of EB-irradiation on $a_{\mathrm{uc}}$ value of silica glass, which is not so easy to form thin sheet because of high glass transition temperature $\left(T_{\mathrm{g}}\right)$ at $1333 \mathrm{~K}$, have been reported. ${ }^{15}$ ) The EB-irradiation enhances the $a_{\mathrm{uc}}$ value. ${ }^{15)}$ Since the EB-irradiation generates the stress relaxation and compressive stress at dangling bonds in silica network structure, the $a_{\mathrm{uc}}$ enhancement of silica glass by EB-irradiation can be explained. ${ }^{15)}$

On the other hand, effects of additional elements on $a_{\mathrm{uc}}$ values of silicate glasses (crown, soda and alkali free glasses) have been studied. ${ }^{16,17)}$ The dissolution driven by the added alkali elements in the one of silicate glass (Crown glass (71 mass\% $\mathrm{SiO}_{2}, 11$ mass $\% \mathrm{Na}_{2} \mathrm{O}, 7$ mass $\% \mathrm{CaO}, 5$ mass $\%$ $\mathrm{K}_{2} \mathrm{O}, 4$ mass $\%$ ZnO, 2 mass $\% \mathrm{BaO}$ )) easily occurs. ${ }^{16)}$

Although the alkali metals desolve in liquid-crystal, the other silicate glass (soda glass (64.4 mass\% $\mathrm{SiO}_{2}, 8.07$ mass $\% \mathrm{~B}_{2} \mathrm{O}_{3}, 7.00$ mass $\% \mathrm{~K}_{2} \mathrm{O}, 6.48$ mass $\% \quad \mathrm{Na}_{2} \mathrm{O}, 4.68$ mass\% $\mathrm{ZnO}, 4.18$ mass\% $\mathrm{Al}_{2} \mathrm{O}_{3}, 4.08$ mass\% $\mathrm{TiO}_{2}, 0.14$ mass $\% \mathrm{Fe}_{2} \mathrm{O}_{3}, 0.58$ mass $\left.\% \mathrm{Sb}_{2} \mathrm{O}_{3}\right)$ ) is often applied to popular liquid-crystal displays with low price, is easily to form the thin sheet because of low $T_{\mathrm{g}}$ value at $830 \mathrm{~K}$. The EB-irradiation with small dose (0.043 MGy) tremendously enhances the $a_{\mathrm{uc}}$ value of soda glass. ${ }^{17)}$ When the EBirradiation cuts the ionic bonding between terminated alkali ions and its chained oxygen atom of silica network structure, the repulsive force probably occurs between the alkali atoms with high density of outer-shell electrons and terminated oxygen atom. Since the intermolecular repulsive force generates the relaxation with compressive stress in front of silica network structure near sites of alkali metals ( $\mathrm{Na}$ and $\mathrm{K}$ ) with chemical weak bonding energies to oxygen of $\mathrm{Na}-\mathrm{O}$ $\left(252 \mathrm{kJmol}^{-1}\right)^{18)}$ and $\mathrm{K}-\mathrm{O}\left(167 \mathrm{kJmol}^{-1}\right),{ }^{18)}$ the enhancement of $a_{\mathrm{uc}}$ value can be explained. ${ }^{17)}$

However, the alkali dissolution is a serious problem for wide liquid-crystal TV display with long life. To prevent dissolution, elements of $\mathrm{Al}$ and $\mathrm{Ca}$ add instead of alkali metals, since the chemical bonding energies of Al-O 
$\left(507 \mathrm{kJmol}^{-1}\right)$ and $\mathrm{Ca}-\mathrm{O}\left(397 \mathrm{kJmol}^{-1}\right)^{18)}$ are larger than those of $\mathrm{Na}-\mathrm{O}\left(252 \mathrm{kJmol}^{-1}\right)$ and $\mathrm{K}-\mathrm{O}\left(167 \mathrm{kJmol}^{-1}\right){ }^{18)}$ Thus, the thin sheet of alkali free glass $\left(60.0\right.$ mass $\% \mathrm{SiO}_{2}$, 17.0 mass $\% \quad \mathrm{Al}_{2} \mathrm{O}_{3}, 8.0$ mass $\% \quad \mathrm{~B}_{2} \mathrm{O}_{3}, \quad 8.0$ mass $\% \quad \mathrm{Sr}_{2} \mathrm{O}_{3}$, 4.0 mass $\% \mathrm{CaO}, 3.0$ mass $\% \mathrm{MgO}$ ) is often utilized for an expensive liquid-crystal TV display with long life. Furthermore, the EB-irradiation with small dose (0.043 MGy) enhances the $a_{\mathrm{uc}}$ value of alkali free glass. ${ }^{19)}$ However, the maximum $a_{\mathrm{uc}}$ value improved by EB-irradiation is not high enough to utilize for super-wide thin glass for its display.

In order to improve the maximum $a_{\mathrm{uc}}$ value by EBirradiation, a borosilicate glass (80.6 mass\% $\mathrm{SiO}_{2}, 11.9$ mass $\% \mathrm{~B}_{2} \mathrm{O}_{3}, 4.4$ mass $\% \mathrm{NaO}$ and 3.1 mass $\% \mathrm{Al}_{2} \mathrm{O}_{3}$ ) is expected, because the bonding energy of boron-oxygen $\left(805 \mathrm{kJmol}^{-1}\right)^{18)}$ is larger than that of silicon-oxygen $\left(794 \mathrm{kJmol}^{-1}\right){ }^{18)}$

On the other hand, since the small bonding energy of sodium-oxygen is $252 \mathrm{kJmol}^{-1}{ }^{18)}$ the $\mathrm{Na}$ addition in the borosilicate glass decreases the $T_{\mathrm{g}}$ value of $833 \mathrm{~K}$ and then induces the good productivity. Furthermore, since EB irradiation with small dose easily cuts the ionic bonding between terminated sodium ions and its chained oxygen in silica network structure, the repulsive force probably occurs between the sodium atoms and terminated oxygen atom of silica network. When the intermolecular repulsive force generates the stress relaxation with compressive stress in silica network structure, it is possible that EB irradiation with small dose may easily enhance the $a_{\mathrm{uc}}$ value of borosilicate glass. Namely, both strengthening by boron addition and shortening the start dose of EB-irradiation to strengthening by sodium addition can be expected for borosilicate glass.

To confirm that, it is possible to strengthen transparent thin glassy sheets for a super-wide liquid-crystal display, the possible beneficial effects of EB irradiation on the $a_{\mathrm{uc}}$ value of borosilicate glass have been investigated.

\section{Experimental Procedure}

\subsection{Sample preparation and impact test}

The atomic fraction of positive ions of borosilicate glass samples (Kobayashi Tokushu Glass, Co., Ltd., Japan) was 8.85 at $\%$ for B, 81.83 at $\%$ for $\mathrm{Si}, 4.74$ at $\%$ for $\mathrm{Al}$ and 4.58 at $\%$ for $\mathrm{Na}$. The sizes of samples measured was $20 \times 10 \times$ $1.0 \mathrm{~mm}$. To evaluate the impact-fracture toughness, the Charpy impact values of the glass samples with and without EB irradiation were measured by using a standard impactfracture-energy measurement system (JIS K 7077-1991). The Charpy impact value is expressed by the following equation: ${ }^{15-17,19)}$

$E=W R\left[(\cos \beta-\cos \alpha)-\left(\cos \alpha^{\prime}-\cos \alpha\right)(\alpha+\beta) /\left(\alpha-\alpha^{\prime}\right)\right]$

where, $E, W, R, \beta, \alpha$ and $\alpha^{\prime}$ are, respectively, the impact fracture energy $(\mathrm{kJ})$, the hammer weight $(\mathrm{N})$, the length $(\mathrm{m})$ of hammer weight point from the rolling center, the start angle before impact, the maximum angle after impact, and the maximum angle of the blank test. The Charpy impact value $\left(\mathrm{kJm}^{-2}\right)$ is given by the following equation:

$$
a_{\mathrm{uc}}=E /(b \times t)
$$

Here, $E, b(=10 \mathrm{~mm})$, and $t(=1.00 \pm 0.005 \mathrm{~mm})$ are the impact fracture energy $(\mathrm{J})$, sample width $(\mathrm{mm})$, and span distance (sample thickness, $\mathrm{mm}$ ). The distance between the supporting points was $11.45 \mathrm{~mm}$.

\subsection{Electron-beam irradiation}

The borosilicate glass sheets were homogeneously irradiated by using an electron-curtain processor (Type CB175/ 15/180L, Energy Science Inc., Woburn, MA, Iwasaki Electric Group Co., Ltd., Tokyo). ${ }^{15,17,19)}$ The specimen was homogeneously irradiated with an electron beam through a titanium window attached to a 240 -mm-diameter vacuum chamber. A tungsten filament in a vacuum was used to generate the electron beam with an electrical potential of $170 \mathrm{kV}$ and an irradiating current of $2.0 \mathrm{~mA}$. To prevent their oxidation, the samples were kept in a nitrogen atmosphere of $0.1 \mathrm{MPa}$ with a residual concentration of oxygen of less than $400 \mathrm{ppm}$. The flow rate of the nitrogen gas was $1.5 \mathrm{Ls}^{-1}$.

The sample, was positioned in an aluminum plate holder $(0.15 \mathrm{~m} \times 0.15 \mathrm{~m})$, and transported on a conveyor at a speed of $9.56 \mathrm{~m} / \mathrm{min}$. Because the minimum dose of EB irradiation was $43.2 \mathrm{kJg}^{-1}\left(1.13 \times 10^{13} \mathrm{em}^{-2}=43.2 \mathrm{kGy}\right)$, each burst of irradiation was performed for a short time $(0.23 \mathrm{~s})$ at $0.043 \mathrm{MGy}$ to avoid excessive heating of the sample. As a result, the temperature of the sample surface remained below $323 \mathrm{~K}$ just after irradiation. Both surfaces of the samples were repeatedly irradiated to increase the total irradiation dose. The interval between the end of one period of irradiation and the start of the next was $30 \mathrm{~s}$. The dosage was proportional to the yield determined from the irradiation current, conveyor speed, and number of irradiations. The yield was calibrated using dose-meters with radio chromic nylon film (FWT-60-00: Far West Technology Inc., Goleta, CA, USA)

The electron number density $\left(\mathrm{em}^{-2}\right)$ was expressed by the following equation in metals. ${ }^{20)}$

$$
N g=D E / C g
$$

Here, $N g\left(\mathrm{em}^{-2}\right)$ is the irradiation dose, $D E\left(\mathrm{Svs}^{-1}\right)$ is the dose equivalent, and $C g$ is the dose equivalent per transferred coefficient of particle flux $\left\{0.1649 \times 10^{-13}\left[\left(\mathrm{Svs}^{-1}\right) /\right.\right.$ $\left.\left.\left(\mathrm{e}\left(\mathrm{m}^{2} \mathrm{~s}\right)^{-1}\right)\right]\right\} .^{20)}$

\subsection{Evaluation of dangling bonds}

To obtain more precise information on atomic-scale structural changes in the glass, the density of the dangling bonds was measured by means of an ESR spectrometer (JESFA2000, Nippon Denshi Ltd., Tokyo). ${ }^{15,17,19)}$ The microwave frequency range used in the ESR analysis was the X-band at $9.45 \pm 0.05 \mathrm{GHz}$ with a field modulation of $100 \mathrm{kHz}$. The microwave power was $1 \mathrm{~mW}$. The magnetic field was varied from 318.7 to $328.7 \mathrm{mT}$. The spin density was calculated by using the $\mathrm{Mn}^{2+}$ standard sample. Only ESR spectra are given, not spin densities. Based on the standard calibration material [4-hydroxy-2,2,6,6-tetra-methylpiperidine-1-oxyl (TEMPOL, 089-04191, Wako Pure Chemical Industries Ltd., Tokyo)] and $\mathrm{Mn}^{2+}$ in the $\mathrm{MnO}$, the density of dangling bonds is estimated by double integration of the intensity of the ESR signal. ${ }^{15)}$ 


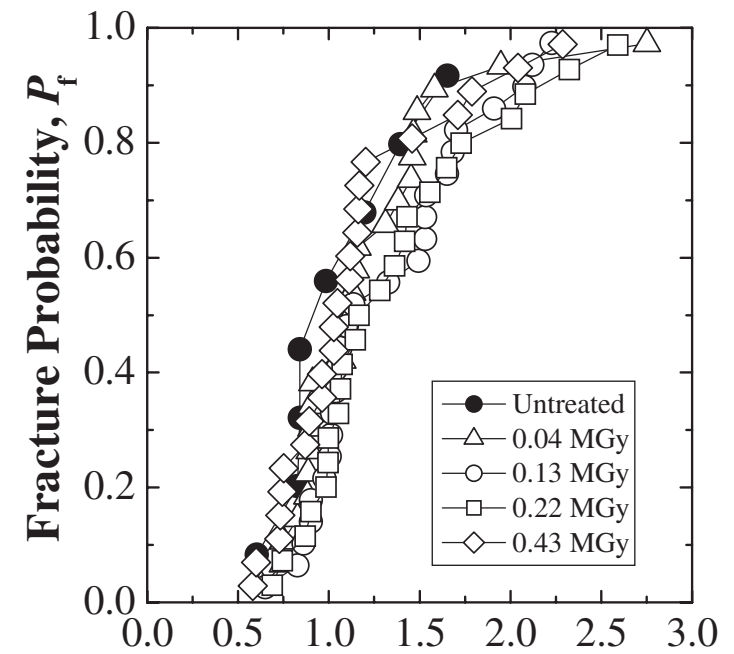

Charpy Impact Value, $a_{\mathrm{uc}} / \mathrm{kJ} \mathrm{m}^{-2}$

Fig. 1 Relationships between Charpy impact value and fracture probability at each EB irradiation dose.

\section{Results}

\subsection{Impact value of borosilicate glass before and after EB-irradiation}

Evaluating the probability of fracture $\left(P_{\mathrm{f}}\right)$ is a convenient method of quantitative analyzing experiment values relating to fracture. $P_{\mathrm{f}}$ is expressed by the following equation, which is a generalized form of the median rank method: ${ }^{21)}$

$$
P_{\mathrm{f}}=(I-0.3) /\left(N_{\mathrm{s}}+0.4\right)
$$

where $n$ and $I$ are the total number of samples $(n=33)$ and the order of fracture of each sample, respectively. Here, the order of fracture is the aligned number of fractured samples from low to high impact value. When the $I$ values are 1 , 12 , and 33 , the $P_{\mathrm{f}}$ values are $0.020,0.350$, and 0.979 , respectively.

Figure 1 plots the relationships between the $P_{\mathrm{f}}$ values and the experimental Charpy impact values $\left(a_{\mathrm{uc}}\right)$ of borosilicate glass irradiated at each dosage. The $a_{\mathrm{uc}}$ values at all $P_{\mathrm{f}}$ values for borosilicate glass irradiated at $0.043-0.22 \mathrm{MGy}$ exceed the corresponding values before irradiation.

Figure 2 presents the experimental impact values $\left(a_{\mathrm{uc}}\right)$ of the borosilicate glass for various electron-beam (EB) irradiation dosages at each $P_{\mathrm{f}}$ value. EB irradiation from 0.04 to $0.22 \mathrm{MGy}$ probably enhances the $a_{\mathrm{uc}}$ value of borosilicate glass from 0.02 to 0.98 of $P_{\mathrm{f}}$ value. The $a_{\mathrm{uc}}$ value at a $P_{\mathrm{f}}$ of 0.020 of borosilicate glass irradiated at a dosage of $0.13 \mathrm{MGy}$ is about 1.37 times greater than that before irradiation. Additional EB irradiation at dosages of 0.22 to $0.43 \mathrm{MGy}$ clearly decreases the impact values. The impact values of samples irradiated at $0.43 \mathrm{MGy}$ are slightly higher than those before irradiation. Consequently, EB-irradiation at 0.04 to $0.22 \mathrm{MGy}$ appears to enhance the $a_{\mathrm{uc}}$ value at each $P_{\mathrm{f}}$ value of borosilicate glass.

\subsection{Dangling-bond formation by EB-irradiation}

No marked differences are found in the X-ray diffraction patterns of the borosilicate glasses recorded before and after
EB Irradiation Dose, $D$ / kJ g ${ }^{-1}$

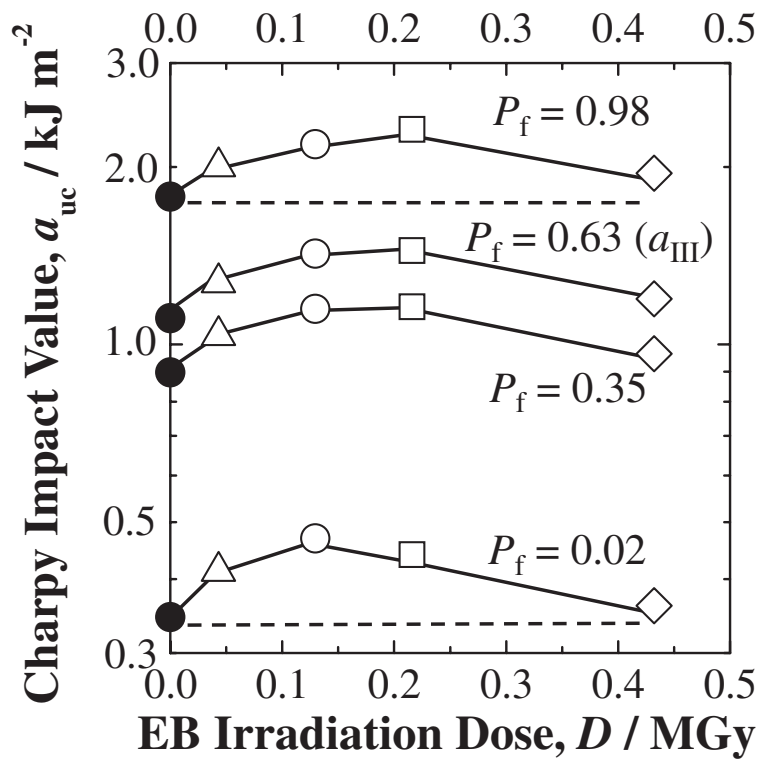

Fig. 2 Change in the impact value versus EB irradiation dosages at different fracture probabilities of borosilicate glass, together with $a_{\mathrm{o}}$ from eq. (6) at $P_{\mathrm{f}}=0.632$.
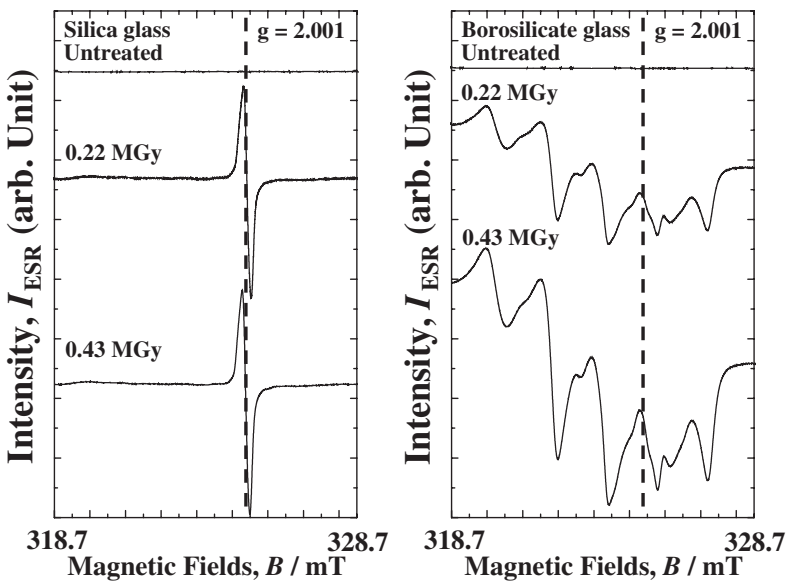

Fig. 3 ESR signals of borosilicate and silica glasses before and after EB irradiation.

EB irradiation. On the other hand, EB irradiation produces detectable dangling bonds. To clarify the effects of EB irradiation on the Charpy impact values, ESR signals related to dangling bonds are recorded.

Figure 3 depicts the ESR signals of borosilicate and silica glasses before and after EB irradiation. Although no ESR signals of the untreated sample can be detected, a sharp ESR signal is observed in the irradiated silica glasses, corresponding to dangling bonds of an E-prime center consisting of a Si$\mathrm{O}$ pair. ${ }^{22,23)}$ In silica glass, each silicon atom is generally coordinated to four atoms of oxygen, whereas a silicon atom with a dangling bond is coordinated to three atoms of oxygen: A silicon atom site with a dangling bond in silica glass is defined as an E-prime center. As illustrated in Fig. 3, EB irradiation at $0.22 \mathrm{MGy}$ enhances the intensity of the ESR signal, demonstrating that dangling bonds are formed in the silica glass. ${ }^{17,18)}$ Furthermore, additional irradiation from 
0.22 to 0.43 MGy enhances the intensity of the ESR signal. The densities of dangling bonds in silica glass samples irradiated at 0.22 and $0.43 \mathrm{MGy}$ are $2.43 \times 10^{16}$ and $3.23 \times$ $10^{16}$ spinsm $^{-3}$, respectively.

Although a sharp ESR signal, corresponding to dangling bonds of an E-prime center consisting of a Si-O pair, ${ }^{17,18)}$ cannot be observed in the irradiated borosilicate glasses, the irradiated borosilicate glass exhibits many ESR signals at different magnetic field values of the top peak, as indicated in Fig. 3. Since the ionic bonding energy between sodium and oxygen $\left(252 \mathrm{kJmol}^{-1}\right)^{18)}$ is smaller than covalent bonding energy of silica glass $\left.\left(794 \mathrm{kJmol}^{-1}\right),{ }^{18}\right) \mathrm{EB}$ irradiation with small dose easily cuts the ionic bonding between terminated sodium ions and its chained oxygen in silica network structure. Namely, apparent dangling bonds constructed with the sodium atoms with high density of outer-shell electrons and terminated oxygen atom of silica net work probably exist in the borosilicate glass.

Since the intensity of ESR signals of borosilicate glass is approximately equal to that of silica after $0.22 \mathrm{MGy}-$ irradiation, the density of apparent dangling bonds in borosilicate glass $\left(1.83 \times 10^{16}\right.$ spinsm $\left.^{-3}\right)$ is approximately equal to that of dangling bonds of silica glass.

Furthermore, additional irradiation ( $0.43 \mathrm{MGy})$ to borosilicate glass enhances the intensity of the ESR signal, which is higher than that at $0.22 \mathrm{MGy}$ and is also apparently higher than that of silica. Thus, the density of dangling bonds in borosilicate glass is $1.28 \times 10^{16}$ spinsm $^{-3}$, which is higher than that $\left(2.21 \times 10^{14}\right.$ spinsm $\left.^{-3}\right)$ of silica glass at $0.43 \mathrm{MGy}$ of additional irradiation.

\section{Discussion}

\subsection{Effect of EB irradiation on the Weibull coefficient}

In order to evaluate the reproducibility (reliability) in comparison with other structural materials, Weibull coefficient $(n)$ is a standard indicator. ${ }^{19)}$ If the statistical equation is assumed to apply to the measured Charpy impact value $\left(a_{\mathrm{uc}}\right)$, the probability of fracture $\left(P_{\mathrm{f}}\right)$ depends on the risk of rupture $\left(a_{\mathrm{uc}} / a_{\mathrm{o}}\right){ }^{24)}$

$$
P_{\mathrm{f}}=1-\exp \left[-\left(a_{\mathrm{uc}} / a_{\mathrm{o}}\right)^{n}\right]
$$

Here, $a_{\mathrm{o}}$ and $n$ are $a_{\mathrm{uc}}$ at $P_{\mathrm{f}}=0.63$ and Weibull coefficient $(n)$, respectively.

Figure 4 presents Weibull plots of borosilicate glass irradiated at various dosages. The slopes $(n)$ for the Weibull plots are obtained.

Figure 5 depicts changes in the $n$ values plotted against the EB irradiation dosage. The $n$ value from $0.043 \mathrm{MGy}$ to $0.13 \mathrm{MGy}$ is larger than that in untreated samples. High $n$ values for borosilicate glass are obtained by EB irradiation at $0.13 \mathrm{MGy}$. Thus, EB irradiation from 0.04 to $0.13 \mathrm{MGy}$ apparently enhances the Weibull coefficient $(n)$ of impact value related to the reproducibility (reliability) of borosilicate glass.

\subsection{Effects of EB-irradiation on the lowest impact value}

Although $n$ value is a standard indicator to evaluate the reproducibility, the Weibull plots at low $P_{\mathrm{f}}$ values apparently deviate from the linear relationship, as shown in Fig. 4. In

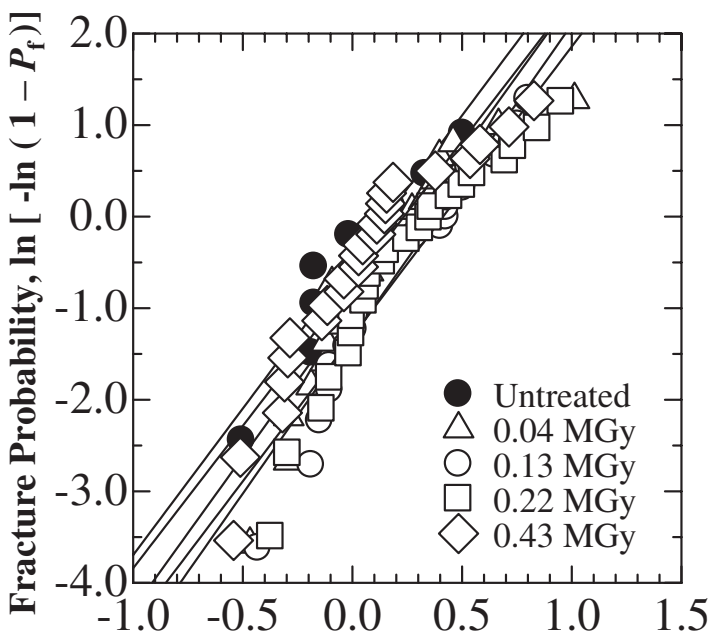

Charpy Impact Value, $\left(\ln a_{\mathrm{uc}} / \mathrm{kJ} \mathrm{m}^{-2}\right)$

Fig. 4 Weibull plots $(n)$ of borosilicate glass irradiated by an electron beam at each dose.

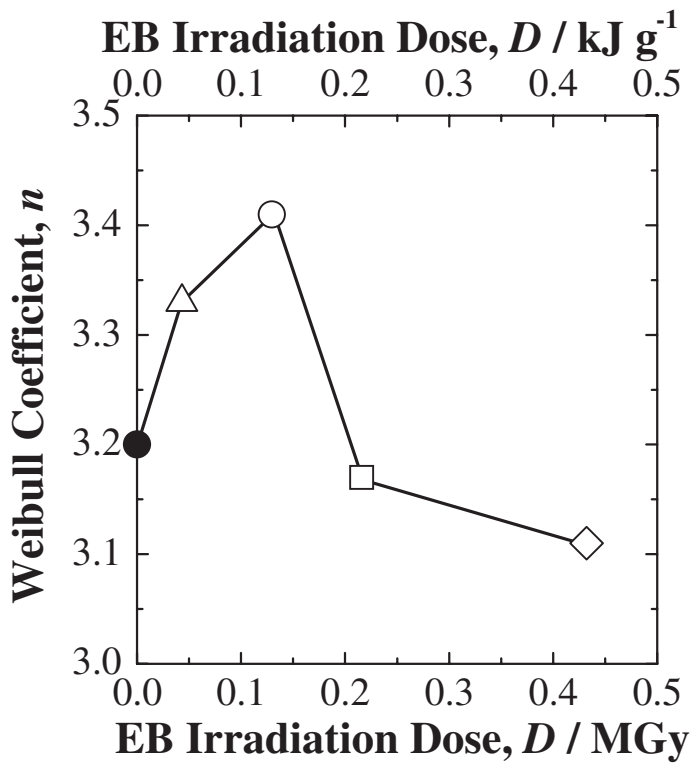

Fig. 5 Changes in Weibull coefficient $(n)$ versus EB irradiation dosages.

order to estimate the impact value at extremely low $P_{\mathrm{f}}$ value, precisely, the lowest impact value $\left(a_{\mathrm{s}}\right)$ for safety design in the three parameter Weibull equation is assumed to get the adaptable relationship with the high correlation coefficient $(F)$. The fracture probability $\left(P_{\mathrm{f}}\right)$ depends on the risk of rupture $\left(\left[a_{\mathrm{uc}}-a_{\mathrm{s}}\right] / a_{\mathrm{III}}\right) .^{25,26)}$

$$
P_{\mathrm{f}}=1-\exp \left[-\left(\left[a_{\mathrm{uc}}-a_{\mathrm{s}}\right] / a_{\mathrm{III}}\right)^{m}\right]
$$

In predicting the required impact value $\left(a_{\mathrm{uc}}\right)$ of the new structural materials, coefficient $(m)$, and constant $\left(a_{\mathrm{III}}\right)$ are the key parameters. The $a_{\mathrm{III}}$ value is the $a_{\mathrm{uc}}$ value at a $P_{\mathrm{f}}$ of 0.632 , when the term $\ln \left[-\ln \left(1-P_{\mathrm{f}}\right)\right]$ is zero. The changes in $a_{\mathrm{III}}$ value in relation to the EB irradiation dose are plotted in Fig. 2. The $a_{\mathrm{III}}$ values of borosilicate glasses irradiated from 0.04 to $0.43 \mathrm{MGy}$ are higher than those before EB irradiation.

When $P_{\mathrm{f}}$ is equal to zero, the $a_{\mathrm{uc}}$ value is defined as the lowest impact value $\left(a_{\mathrm{s}}\right)$. Figure 6 plots changes in the 


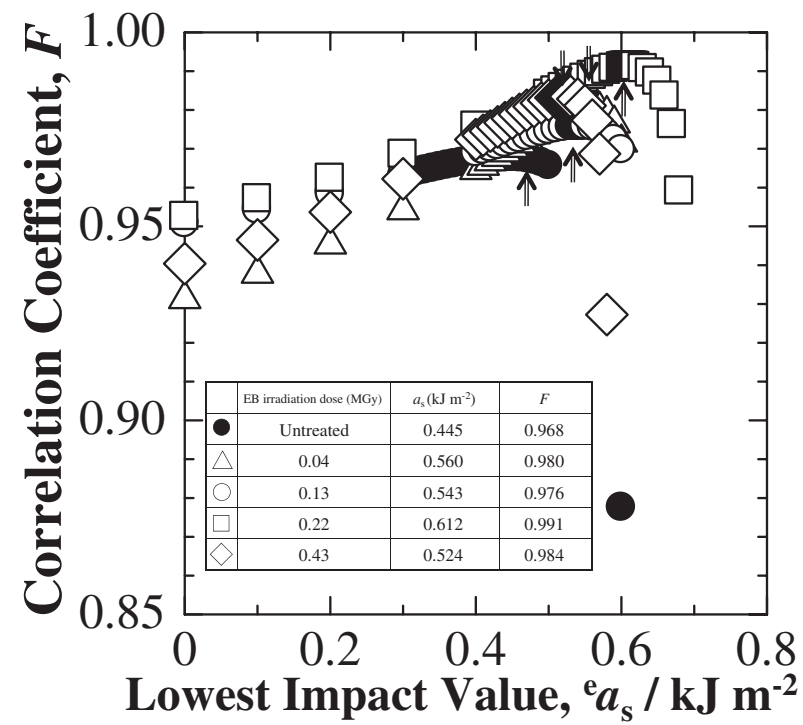

Fig. 6 Changes in correlation coefficient $(F)$ versus the potential $a_{\mathrm{s}}$ value ( $\left.{ }^{\mathrm{e}} a_{\mathrm{s}}\right)$. The lowest impact value $\left(a_{\mathrm{s}}\right)$ was determined at maximum $F$.

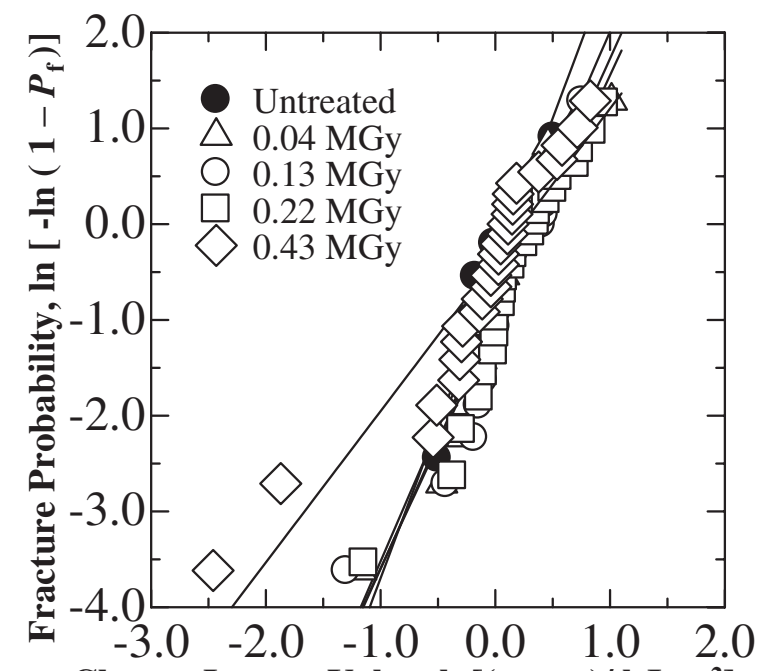

Charpy Impact Value, $\ln \left[\left(a_{\mathrm{uc}}-a_{\mathrm{s}}\right) / \mathrm{kJ} \mathrm{m}^{-2}\right]$

Fig. 7 Linear relationships between $\left(a_{\mathrm{uc}}-a_{\mathrm{s}}\right)$ and $\ln \left[-\ln \left(1-P_{\mathrm{f}}\right)\right]$ for borosilicate glass irradiated by electron beams at each dosage.

correlation coefficient $(F)$ with respect to the potential $a_{\mathrm{s}}$ value ( ${ }^{\mathrm{e}} a_{\mathrm{s}}$ ) estimated from eq. (6). The $a_{\mathrm{s}}$ value is the ${ }^{\mathrm{e}} a_{\mathrm{s}}$ value at the maximum $F$ value.

Figure 7 illustrates the linear relationships for borosilicate glass irradiated at each dosage. The values of $a_{\mathrm{III}}$ and $m$ are determined by the least-squares method. The $\mathrm{m}$ value is estimated by the slope of the relationship when the $a_{\mathrm{s}}$ value is first decided.

Figure 8 presents variations in the $a_{\mathrm{s}}$ value of borosilicate glass versus the EB irradiation dose, together with the low experimental $a_{\mathrm{uc}}$ value at $P_{\mathrm{f}}=0.02$. Here, $a_{\mathrm{s}}$ is always lower than the experimental $a_{\mathrm{uc}}$ value. The $a_{\mathrm{s}}$ of borosilicate glass irradiated from 0.04 to $0.22 \mathrm{MGy}$ is $1.3 \pm 0.1$ times higher than that before irradiation.

Therefore, EB irradiation from 0.04 to $0.22 \mathrm{MGy}$ apparently enhances the $a_{\mathrm{s}}$ value of impact value related to reliability of borosilicate glass.

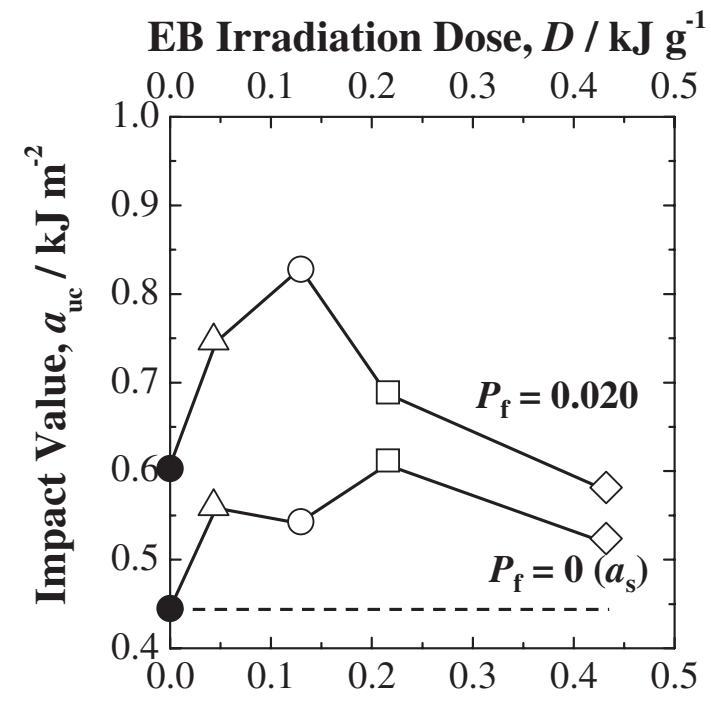

EB Irradiation Dose, D / MGy

Fig. 8 Change in the impact value against EB irradiation dosages at different fracture probabilities of borosilicate glass.

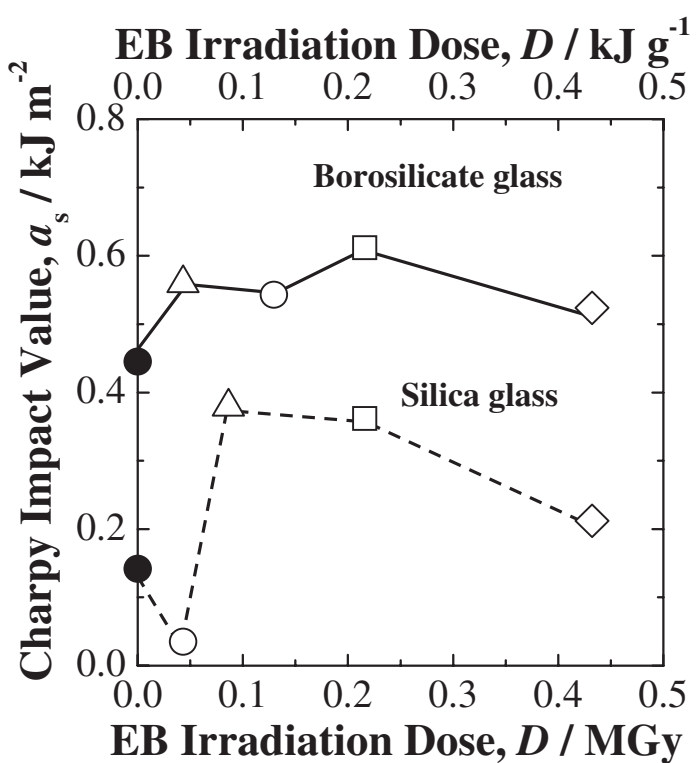

Fig. 9 Variations of the lowest impact value $\left(a_{\mathrm{s}}\right)$ for silica (Ref. 15) and borosilicate glasses versus EB irradiation dose.

\section{3 $a_{\mathrm{s}}$ enhancement of borosilicate glass by irradiation with small dose}

Based on the covalent bonding energies (805 and $\left.794 \mathrm{kJmol}^{-1}\right)^{18)}$ between oxygen and positive (B and $\mathrm{Si}$ ) elements, both strengthening the $a_{\mathrm{s}}$ value by boron addition and shortening the start dose to the $a_{\mathrm{s}}$ enhancement can be expected for borosilicate glass. Figure 9 depicts changes in the $a_{\mathrm{s}}$ value for silica and borosilicate glasses versus EB irradiation dose. The $a_{\mathrm{s}}$ value of borosilicate glass is always higher than that of silica glass. Since the bonding energy between boron and oxygen is higher than that of silicon and oxygen, the boron addition probably enhances the $a_{\mathrm{s}}$ value.

On the other hand, the start point of irradiation dose to strengthening the $a_{\mathrm{s}}$ value of borosilicate is shorter than that of silica glass (see Fig. 9). Since the bonding energy 
between sodium and oxygen $\left(252 \mathrm{kJmol}^{-1}\right)^{18)}$ is smaller than that of silica glass $\left.\left(794 \mathrm{kJmol}^{-1}\right),{ }^{18}\right) \mathrm{EB}$ irradiation with small dose easily cuts the ionic bonding between terminated sodium ions and its chained oxygen in silica network structure. Thus, the repulsive force probably occurs between the sodium atoms with high density of outer-shell electrons and terminated oxygen atom of silica network. As illustrated in Fig. 3, the complex ESR signals are found in the borosilicate glass initially irradiated at $0.04 \mathrm{MGy}$. When the repulsive force generates the stress relaxation with compressive stress in silica network structure, it is possible that EB-irradiation with small dose easily enhances the $a_{\mathrm{uc}}$ value of borosilicate glass.

\subsection{High resistance to irradiation damage of borosili- cate glass}

Additional EB irradiation at $0.43 \mathrm{MGy}$ remarkably decreases the $a_{\mathrm{s}}$ value of the glasses, because the additional dangling bonds (high density of dangling bonds) act as a crack origins and crack pass in the borosilicate glass. Although the large start point of irradiation dose to decrease the $a_{\mathrm{s}}$ value is $0.08 \mathrm{MGy}$ for silica glass, it is $0.22 \mathrm{MGy}$ for borosilicate glass. Consequently, the strong resistance to irradiation damage of borosilicate glass is qualitatively confirmed.

On the other hand, this influence can be explained by complex ESR signals in Fig. 3. Additional irradiation (0.43 MGy) to borosilicate glass enhances the intensity of the ESR signal, which is remarkably higher than that of silica. The density of dangling bonds in borosilicate glass is higher than that of silica glass after additional irradiation at $0.43 \mathrm{MGy}$. Based on the covalent bonding energies (805 and $\left.794 \mathrm{kJmol}^{-1}\right)^{18)}$ between oxygen and positive (B and $\mathrm{Si}$ ) elements, the dangling bond formation at boron-oxygen is not easier than that at silicon-oxygen. Thus, the ESR signals of borosilicate glass is the dangling bonds of silicon-oxygen pairs, as well as the apparent dangling bonds constructed with free sodium atoms with high density of outer-sell electrons and terminated oxygen atoms of polarized silica network. The strong resistance to irradiation damage of borosilicate glass is explained, when the boron addition probably reinforces the resistivity to irradiation damage of silica network structure.

\subsection{Influence of nanostructure change on impact value of borosilicate glass}

Annealed borosilicate glass is brittle because of the sharp potential curve of the tight network structure with high atomic density. The sharp potential curve probably exhibits a strong inter-atomic force of chemical bonding at the minimum value of the curve of annealed borosilicate glass.

EB irradiation provides the $796,805,252,507 \mathrm{kJmol}^{-1}$ (here, based on the atomic mass $\left(19.56 \mathrm{gmol}^{-1}\right)$ of borosilicate glass. One $\mathrm{kJmol}^{-1}$ irradiation energy corresponds to $5.11 \times 10^{-2} \mathrm{MGy}\left(=51.1 \mathrm{Jg}^{-1}\right)$-irradiation dose.) of energy necessary to break chemical bonds between $\mathrm{Si}-\mathrm{O}, \mathrm{B}-\mathrm{O}$, $\mathrm{Na}-\mathrm{O}$, and $\mathrm{Al}-\mathrm{O}$ pairs. ${ }^{18)}$

Based on the height enhancement of electron spin resonance (ESR) spectra, EB irradiation formed apparent and real dangling bonds in a silica glassy network structure.
If EB irradiation results in the formation of apparent dangling bonds from $\mathrm{Na}-\mathrm{O}$ pairs (see Fig. 3), this should result in a partial relaxation of residual molecular strains and compressive stress in the silica glass network structure.

Since the outer-shell electron at terminated atoms of the relaxation sites (dangling bonds) between terminated oxygen and positive atoms exhibit the repulsive force dangling bonds act as atomic scale cushions against applied stress. Generating both compressive stress and relaxation of residual stress in front of crack tip prevents to the crack generation and propagation. Thus, EB-irradiation enhances both $a_{\mathrm{uc}}$ and $a_{\mathrm{s}}$ values of the borosilicate glass.

When the interatomic distances of the bonded $\mathrm{Si}-\mathrm{O}$ pairs are optimal in terms of the interatomic potential curve, relaxation increases the bonding energy of the network structure, possibly allowing an enhancement of compressive stress in its surface. Therefore, we conclude that both enhancement of the compressive stress in the surface of borosilicate glass and relaxation of the silica network contribute to increasing the impact value of the borosilicate glass (Figs. 2 and 8). Namely, to improve the $a_{\mathrm{uc}}$ value, EBirradiation from 0.04 to $0.22 \mathrm{MGy}$ probably introduces both compressive zone and relaxation sites at mostly apparent (Na-O) dangling bonds, which density is $1.83 \times 10^{16}$ spinsm $^{-3}$ at $0.22 \mathrm{MGy}$ (see Fig. 3).

On the other hand, an additional (excessive) EB irradiation dose of more than $0.43 \mathrm{MGy}\left(\mathrm{kJg}^{-1}\right)$ apparently decreases the impact value (Figs. 2 and 8). Because irradiation mainly breaks bonds between Si-O pairs, additional irradiation from 0.22 to $0.43 \mathrm{MGy}$ increases the density of real dangling bonds from $1.83 \times 10^{16}$ to $3.76 \times 10^{16}$ spinsm $^{-3}$ (see Fig. 3) in the glass network structure. The high density of dangling bonds probably results in linking of cracks and acceleration of crack propagation; this may explain the deterioration in the $a_{\mathrm{uc}}$ values of samples irradiated from 0.22 to $0.43 \mathrm{MGy}$.

Therefore, the optimum density of apparent dangling bonds with the high impact value induced by $0.22 \mathrm{MGy}-\mathrm{EB}$ irradiation is $1.83 \times 10^{16} \mathrm{spinsm}^{-3}$.

\subsection{Penetration depth of electron beam in borosilicate glass}

Christenhusz and Reimer evaluated the depth of EB irradiation penetration of less than $200 \mathrm{kV}$ electrical potential by measuring the Joule heat generated in copper films. ${ }^{27)}$ Based on density $\left(\rho: \mathrm{kg} / \mathrm{m}^{3}\right)$ and potential drop $(\Delta V: \mathrm{kV})$, penetration depth $\left(D_{\mathrm{th}}: \mathrm{m}\right)$ was given by

$$
D_{\text {th }}=66.7 \times \Delta V^{5 / 3} / \rho .
$$

The potential at the surface sample $\left(V_{\mathrm{s}}\right)$ was expressed by the following equation. ${ }^{27)}$

$$
V_{\mathrm{s}}=V_{\mathrm{o}}-\Delta V
$$

Based on the assumption of Christenhusz and Reimer, the potential drop $(\Delta V)$ was caused by the irradiation energy loss of the electron beam from the initial potential at the filament surface of the electron beam gun $\left(V_{\mathrm{o}}\right)$ to the potential at the surface sample $\left(V_{\mathrm{s}}\right)$. The potential drop $(\Delta V)$ was expressed by the following equation. ${ }^{27)}$

$$
\Delta V=\tau \cdot V_{\mathrm{o}} / S
$$


Here, $\tau$ is thickness, and $S$ is the mass thickness of the Ti sheet and nitrogen gas.

The electrical potential $(128 \mathrm{keV})$ was estimated from the initial electrical potential $(170 \mathrm{keV})$, the thickness $[1.0 \times$ $\left.10^{-5} \mathrm{~m}(10 \mu \mathrm{m})\right]$ of the titanium window $\left[\rho=4540 \mathrm{~kg} / \mathrm{m}^{3}\right.$ $\left.\left(4.54 \mathrm{~g} / \mathrm{cm}^{3}\right)\right]$, and the distance $(30 \mathrm{~mm})$ in the nitrogen gas atmosphere $\left(\rho=1.13 \mathrm{~kg} / \mathrm{m}^{3}\right)$ between the surface of the sample and the window. Since the electrical potential was $128 \mathrm{keV}$, eq. (7) estimated by Christenhusz and Reimer predicts that the penetration depth $\left(D_{\mathrm{th}}: \mathrm{m}\right)$ of borosilicate glass, which density $(\rho)$ was $2230 \mathrm{~kg} / \mathrm{m}^{3}$, should be $99.8 \mu \mathrm{m}$.

The penetration depth (Libby assumption ${ }^{28)}$ ) of EB irradiation related to mass thickness $\left(S: \mathrm{mg} / \mathrm{cm}^{2}\right)$ and irradiation voltage $\left(V_{\mathrm{s}} / \mathrm{kV}\right)$ is expressed by

$$
S=1 / 150 \times \Delta V^{5 / 3} .
$$

The estimated mass thickness was $34.8 \mathrm{mg} / \mathrm{cm}^{2}$ when the initial irradiation voltage was $170 \mathrm{keV}$. Since the mass thickness of the Ti foil $\left(1.78 \mathrm{mg} / \mathrm{cm}^{2}\right)$ and $\mathrm{N}_{2}$ gas $(0.15 \mathrm{mg} /$ $\mathrm{cm}^{2}$ ) reduced the penetration depth of $\mathrm{EB}$ irradiation, the mass thickness $(S)$ of the glass sample was $32.9 \mathrm{mg} / \mathrm{cm}^{2}$. In addition, the electrical potential of the sample surface was expressed by

$$
\Delta V=(150 \times S)^{3 / 5} .
$$

Based on the Libby assumption, ${ }^{28)}$ the penetration depth of borosilicate glass was $145.1 \mu \mathrm{m}$.

Since the mean value of penetration (irradiated) depth at both broad surface sides of borosilicate glass is $122 \pm 23 \mu \mathrm{m}$, the irradiated thickness from surface is $24 \pm 5 \%$ of the sample thickness $(1.0 \mathrm{~mm})$.

\section{Conclusion}

The effect of homogeneous electron-beam (EB) irradiation with low voltage on the Charpy impact value $\left(a_{\mathrm{uc}}\right)$ of borosilicate glass was studied.

(1) EB irradiation of less than $0.216 \mathrm{MGy}$ enhanced the $a_{\mathrm{uc}}$ value.

(2) EB irradiation of less than $0.216 \mathrm{MGy}$ enhanced the Weibull coefficient $(n)$.

(3) The lowest impact value $\left(a_{\mathrm{s}}\right)$, estimated by the modified Weibull equation with three parameter, was defined to be the $a_{\mathrm{uc}}$. value at zero of fracture probability $\left(P_{\mathrm{f}}\right)$. EB irradiation from 0.043 to $0.216 \mathrm{MGy}$ apparently enhanced the $a_{\mathrm{s}}$ value of borosilicate glass. The $a_{\mathrm{s}}$ of borosilicate glass irradiated from 0.043 to $0.216 \mathrm{MGy}$ was $1.3 \pm 0.1$ times higher than that before irradiation.

(4) The $a_{\mathrm{s}}$ value of borosilicate glass was higher than the $a_{\mathrm{s}}$ value of silica glass.

(5) The effective EB irradiation dose for generating the high $a_{\mathrm{s}}$ value of borosilicate glass was smaller than that of silica glass.

(6) Based on the increasing height of the electron-spin resonance (ESR) spectra, the initial EB-irradiation with small dose formed the apparent dangling bonds con- structed with the sodium atoms with high density of outer-shell electrons and terminated oxygen atom of silica net work in borosilicate glass. If both partial relaxation of the deformation strain and compressive stress in front of crack tip mainly occurred, the initial enhancement of $a_{\mathrm{uc}}$ value by the initial EB-irradiation could be explained.

(7) Furthermore, the strong resistance to irradiation damage of borosilicate glass was qualitatively confirmed. Although the large start point of irradiation dose to decrease the $a_{\mathrm{s}}$ value was $0.08 \mathrm{MGy}$ for silica glass, it was $0.22 \mathrm{MGy}$ for borosilicate glass. Consequently, the boron addition enhanced the resistivity to irradiation damage.

\section{Acknowledgements}

This work was partly supported by the JSPS scholarship of Research Fellow program.

\section{REFERENCES}

1) K. Maeda: J. Jpn. Soc. Precision Eng. 70 (2004) 466-469.

2) S. Miwa: New Glass. 18 (2003) 7-11.

3) K. Niihara: Ceramics Jpn. 21 (1986) 581-589.

4) M. Sakai: Ceramics Jpn. 27 (1992) 281-287.

5) A. A. Griffith: Phil. Trans. Roy. Soc. A 221 (1920) 163-198.

6) S. Inoue, T. Uchiyama and K. Niihara: Ceramics Jpn. 21 (1986) 621629.

7) T. Sato and M. Shimada: Ceramics Jpn. 21 (1986) 613-619.

8) A. L. Zijlstra and A. J. Burggraaf: J. Non-Cryst. Solids 1 (1968) 49-68.

9) Y. Nishi, H. Harano, T. Fukunaga and K. Suzuki: Phys. Rev. B 37 (1988) 2855-2860.

10) Y. Nishi and H. Harano: J. Appl. Phys. 63 (1988) 1141-1143.

11) Y. Nishi, T. Kai and N. Inoue: J. Mater. Sci. Lett. 5 (1986) 1135-1136.

12) N. Yamaguchi, K. Oguri, A. Tonegawa and Y. Nishi: J. Japan Inst. Metals 68 (2004) 198-201.

13) Y. Nishi, A. Kadowaki and T. Shinoda: Mater. Trans. 45 (2004) 33143317.

14) K. Iwata and Y. Nishi: Mater. Trans. 50 (2009) in press.

15) K. Iwata and Y. Nishi: Mater. Trans. 49 (2008) 2058-2062.

16) Y. Taira, K. Iwata and Y. Nishi: J. Japan Inst. Metals 73 (2009) 52-57.

17) Y. Nishi and K. Iwata: Mater. Trans. 46 (2005) 2241-2245.

18) J. B. Pedley and E. M. Marshall: J. Phys. Chem. Ref. Data 12 (1983) 967-1031.

19) Y. Nishi and K. Iwata: Mater. Trans. 47 (2006) 1810-1814.

20) N. Tsuoulfanidis: Measurement and Detection of Radiation, (Houshasen Keisoku no riron to enshu), (Gendai Kougaku sha, 1983) pp. 543-552. (in Japanese)

21) T. Nishida and E. Yasuda: Evaluation of dynamic properties of ceramics, (Ceramics no rikigaku tokusei hyouka), (Nikkan Kogyou Shimbun Sha, Tokyo, 1986) pp. 50-51. (in Japanese)

22) D. L. Griscom and E. J. Friebele: Radiat. Eff. 65 (1982) 303-312.

23) D. L. Griscom: The Centenial Memorial Issue of the Ceramic Soc. Jpn. 99 (1991) 923-942.

24) W. Weibull: Ingeniörs vetenskaps akademien, nr. 151 (Generalstabens litografiska anstalts förlag, Stockholm, 1939) pp. 12-14.

25) Y. Nishi, H. Kobayashi and M. Salvia: Mater. Trans. 48 (2007) 19241927.

26) W. Weibull: Ingeniörs vetenskaps akademien, nr. 153 (Generalstabens litografiska anstalts förlag, Stockholm, 1939) pp. 16-22.

27) R. Christenhusz and L. Reimer: Z. Angew. Phys. 23 (1967) 396-404.

28) W. F. Libby: Anal. Chem. 19 (1947) 2-6. 